\title{
EVAPORATION AND COMBUSTION BEHAVIOR OF LIQUID FUE UNDER NORMAL AND MILD COMBUSTION TECHNIQUES
}

Mahmoud Mohammed, Hesham Abdel Hameed

\begin{abstract}
The combustion performance and emissions of liquid fuel are mainly influenced by its atomization, relative motion of fuel droplets with air, evaporation of the droplets and mixing of fuel vapor and air. The present work represents a simulation analysis of the vaporization and burning of liquid fuel using two different combustion techniques. These two techniques are the normal and Mild and Intense Low oxygen Dilution "MILD" combustion. Isooctane is taken as fuel with the same droplet size distributions for the two models. The commercial code "FLUENT 6.2.3" is used to solve the conservation equations of mass, momentum, energy and transport equations of species concentrations. Turbulence, combustion and radiation modeling in addition to NOx modeling equations are solved together to represent finally temperature and NOX distribution inside the burner. All the models are considered 2D axisymmetric. The combustion process has been simulated as non-premixed and non-adiabatic. The two models show nearly complete combustion behavior but big differences appear regarding NOx emissions and temperature distributions. Lower NOx emissions are produced for MILD combustion. Also for this type of combustion, more uniform temperature distribution and lower peak temperature value are noticed throughout the combustion domain.
\end{abstract}

